\title{
An optimization approach to determining the power of active filters
}

\author{
Lidiia I. Kovernikova ${ }^{1,2 *}$, Ngoc H. Bui ${ }^{2}$, Oleg N. Voitov ${ }^{1}$, Ludmila V. Semenova ${ }^{1}$ \\ ${ }^{1}$ Melentiev Energy Systems Institute SB RAS, Irkutsk, Russian Federation \\ ${ }^{2}$ Irkutsk National Research Technical University, Irkutsk, Russian Federation
}

\begin{abstract}
The coal grading plants in Vietnam extensively apply asynchronous motors with frequency control. They consume reactive power and non-sinusoidal current from the supply network. The nonsinusoidal currents and voltages lead to additional energy losses in electrical equipments, reduce their service life and cause an economic damage. Because of the low load power factor the companies with such plants pay penalties to power supply utilities. These problems can be solved by the active filters. The paper suggests an optimization algorithm to calculate the power of the active filter, which provides a load power factor corresponding to the normative documents and power quality indices corresponding to the standard requirements. The algorithm is used to calculate the power of the active filter for the coal grading plant owned by the company "Kua Ong-Vinakomin".
\end{abstract}

\section{Introduction}

Coal mining is one of the most important economic industries of Vietnam. Mines and quarries have coal grading plants. The manufacturing equipment of the plants is driven by asynchronous motors, primarily with frequency control. They are nonlinear loads for power supply systems and distort power quality. The harmonic factors of voltage exceed the established standards [1]. Voltages and currents contain both harmonics and interharmonics. The load power factors are lower than the value agreed by the normative documents [2].

An active filter is suggested in [3-7] to solve the problems of the load power factor, harmonics and interharmonics.

The paper presents an analysis of the power supply system of the coal grading plant, results of the tests of electric power, formulates an optimization problem and describes an algorithm to determine the power of the active filter, presents results of calculation of the power of active filter for the coal grading plant of the company "Kua Ong-Vinakomin".

\section{Characteristic of the power supply system and loads of the coal grading plant}

Coal is mined in the quarry and transported to the warehouse of the coal grading plant. Fig.1 presents a scheme of the power supply of the plant. Electric power from the $22 \mathrm{kV}$ substation buses of the power supply utility (node 6643) is supplied to the $0.4 \mathrm{kV}$ network of the power supply system of the plant (node 4143) by the
$1000 \mathrm{kVA}$ step-down transformer that belongs to the coal grading plant. The distance between nodes 4143 and 45038 is 60 meters. The total length of the $0.4 \mathrm{kV}$ electric network exceeds $12 \mathrm{~km}$. The plant has two coal grading shops (shop No.1, shop No. 2), a shop of power and water supply, a coal warehouse. In the warehouse the excavator loads coal on the conveyer, which delivers coal to the shops for grading coal pieces by size. The manufacturing equipment of the shops is put into operation by 58 asynchronous motors with a capacity from 4 to $185 \mathrm{~kW}$ primarily with frequency control.

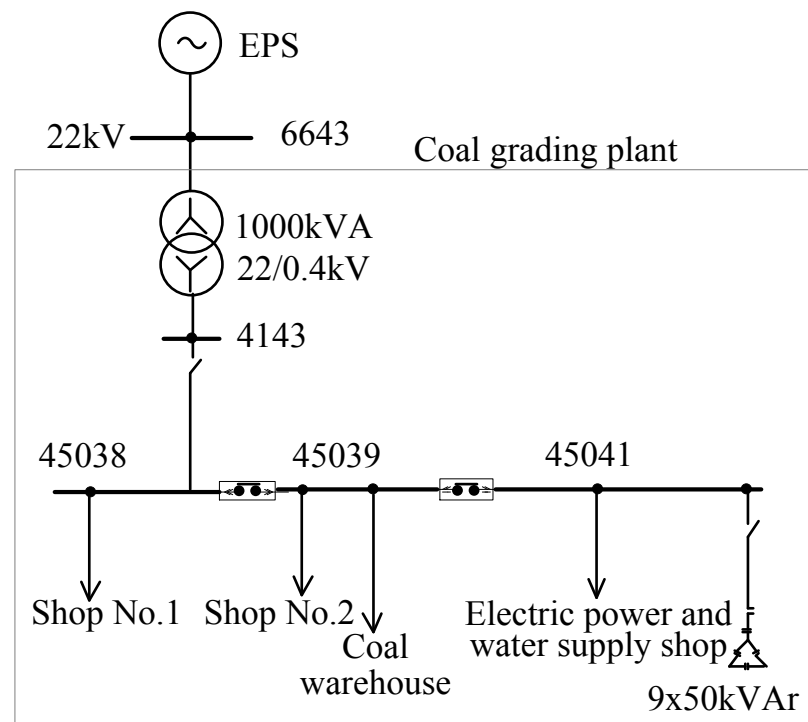

Fig. 1. Power supply system of the coal grading plant.

* Corresponding author: kovernikova@isem.irk.ru 
To assess the quality of voltage and current in the $0.4 \mathrm{kV}$ network, the following indices and norms for their values were established in [1]:

- deviation of the voltage value $-\delta U \leq \pm 5.0 \%$;

- the total harmonic distortion $-K_{U} \leq 6.5 \%$;

- the $n$-th harmonic factor of voltage $-K_{U(n)} \leq 3 \%$;

- the $n$-th harmonic factor of current $K_{I(n)} \leq 12 \%$.

In [2] the load power factor $(\cos \varphi)$ at the connection node of the plant to the supply network should comply with the condition: $\cos \varphi \geq 0.85$. If this condition is not fulfilled, the company with the plant pays penalties to the power supply utility. The value of $\cos \varphi$ can be low because of large reactive power consumption by the electric motors of the plant, active power losses when transmitted over the electric network and losses caused by harmonics and interharmonics. The power quality and the value of $\cos \varphi$ at node 4143 were tested.

\section{Results of the electrical energy tests}

The tests included measurements of the indices of voltage and current quality and $\cos \varphi$ by the device PQBox150 [8] for 24 hours with a time interval of measurements equal to 1 second.

Table 1 presents the measured values of $\delta U$, which correspond to the requirements [1]. The Table also shows the measured values of $K_{U}$ and their normative values from [1].The measured values of $K_{U}$ exceed the norm more than twice. They are shown in bold type.

Table 1. Measured $\delta U, K_{U}, \%$.

\begin{tabular}{|l|c|c|c|}
\hline Parameter & Phase A & Phase B & Phase C \\
\hline$\delta U_{\max }$ & 4.1 & 4.5 & 4.6 \\
\hline$\delta U_{\min }$ & -1.3 & -1.7 & -1.4 \\
\hline$\delta U_{\text {norm }}$ & \multicolumn{3}{|c|}{$\leq \pm 5.0$} \\
\hline$K_{U \max }$ & $\mathbf{1 6 . 8}$ & $\mathbf{1 5 . 3}$ & $\mathbf{1 7 . 1}$ \\
\hline$K_{\text {Unorm }}$ & \multicolumn{3}{|c|}{} \\
\hline
\end{tabular}

Table 2 presents the measured and normative values of $K_{U(n)}$ and $K_{I(n)}$ for the harmonics with the most frequent excess of the norms [1]. The measured values of $K_{I(n)}$ are not higher than the normative value.

Table 2. Measured $K_{U(n)}, K_{I(n)}, \%$.

\begin{tabular}{|l|c|c|c|c|c|c|c|}
\hline \multirow{2}{*}{ Parameter } & \multicolumn{7}{|c|}{ Harmonic } \\
\cline { 2 - 8 } & 3 & 5 & 7 & 11 & 13 & 17 & 23 \\
\hline$K_{U(n) \max A}$ & 2.5 & $\mathbf{1 2 . 7}$ & $\mathbf{1 2 . 8}$ & $\mathbf{4 . 6}$ & 2.1 & $\mathbf{3 . 3}$ & $\mathbf{3 . 1}$ \\
\hline$K_{U(n) \max B}$ & $\mathbf{3 . 9}$ & $\mathbf{1 2 . 3}$ & $\mathbf{1 1 . 8}$ & $\mathbf{4 . 6}$ & $\mathbf{3 . 1}$ & 2.7 & 2.8 \\
\hline$K_{U(n) \max C}$ & 2.0 & $\mathbf{1 2 . 3}$ & $\mathbf{1 2 . 8}$ & $\mathbf{3 . 6}$ & 2.8 & $\mathbf{3 . 4}$ & $\mathbf{3 . 4}$ \\
\hline$K_{U(n) \text { norm }}$ & \multicolumn{7}{|c|}{$\leq 3.0$} \\
\hline$K_{I(n) \max A}$ & 7.1 & 6.8 & 6.7 & 3.9 & 1.9 & 2.3 & 2.7 \\
\hline$K_{I(n) \max B}$ & 3.9 & 4.2 & 1.7 & 0.8 & 1.1 & 0.5 & 0.4 \\
\hline$K_{I(n) \max C}$ & 3.6 & 4.9 & 3.3 & 1.2 & 1.7 & 1.5 & 1.2 \\
\hline$K_{I(n) \text { norm }}$ & \multicolumn{7}{|c|}{$\leq 12.0$} \\
\hline
\end{tabular}

The measured values of $K_{U(m)}$ for interharmonics and the values of currents $I_{(m) \max }$ of interharmonics $(m-$ the number of the interharmonic) are given in Table 3 . The normative values for them are not determined. The measured values of $\cos \varphi$ and its normative value determined in [2] are shown in Table 4. At phase B the value of $\cos \varphi$ is lower than the norm.

Table 3. Measured $K_{U(m)}, \%, I_{(m)}$, A.

\begin{tabular}{|l|c|c|c|c|c|c|c|}
\hline \multirow{2}{*}{ Parameter } & \multicolumn{7}{|c|}{ Interharmonic } \\
\cline { 2 - 8 } & 1.5 & 3.5 & 5.5 & 7.5 & 17.5 & 19.5 & 21.5 \\
\hline$K_{U(\operatorname{m}) \max A}$ & 3.9 & 1.0 & 1.7 & 1.8 & 1.2 & 1.5 & 2.3 \\
\hline$K_{U(m) \max B}$ & 3.3 & 0.8 & 1.9 & 1.9 & 1.0 & 1.3 & 2.3 \\
\hline$K_{U(\operatorname{m}) \max C}$ & 3.8 & 0.9 & 0.9 & 1.2 & 1.7 & 1.7 & 1.7 \\
\hline$I_{(m) \max A}$ & 16.6 & 6.0 & 5.1 & 4.3 & 7.5 & 8.5 & 9.6 \\
\hline$I_{(m) \max B}$ & 17.2 & 4.8 & 5.0 & 2.7 & 1.9 & 2.7 & 3.2 \\
\hline$I_{(m) \max C}$ & 18.0 & 7.3 & 6.4 & 5.3 & 9.2 & 9.7 & 7.5 \\
\hline
\end{tabular}

Table 4. Measured $\cos \varphi$, p.u.

\begin{tabular}{|l|c|c|c|}
\hline Parameter & Phase A & Phase B & Phase C \\
\hline $\cos \varphi_{\max }$ & 0.98 & 0.92 & 0.99 \\
\hline $\cos \varphi_{\min }$ & 0.89 & $\mathbf{0 . 7 2}$ & 0.89 \\
\hline $\cos \varphi_{\text {norm }}$ & \multicolumn{3}{|c|}{$\geq 0.85$} \\
\hline
\end{tabular}

The problems caused by harmonics, interharmonics and $\cos \varphi$ can be resolved using the active filter that is connected to the network in parallel to the nonlinear load.

\section{Optimization problem to determine the power of the active filter}

The power of the active filter is determined by the reactive power that it must generate to compensate for the reactive power of the load and the apparent power required to get rid of harmonics and interharmonics of the current at the point of its connection to the network. This can be achieved by solving an optimization problem with the objective function assumed to be the minimum active power losses in the power system network after installation of the active filter, i.e.

$$
\sum_{n=1}^{N} \Delta P_{(n)}+\sum_{m=1.5}^{M} \Delta P_{(m)}=\min ,
$$

where $N$ - the highest number of harmonic, $M-$ the highest number of interharmonic. In this case the following constraints are to be met:

$$
\begin{gathered}
0.95 \leq \cos \varphi \leq 1.0, \\
U_{\text {min }} \leq U_{i} \leq U_{\text {max }}, \\
K_{U(n) \text { min }} \leq K_{U(n) f} \leq K_{U(n) \max }, \\
K_{U \text { min }} \leq K_{U f} \leq K_{U \text { max }}, \\
K_{I(n) \text { min }} \leq K_{I(n) f} \leq K_{I(n) \text { max }},
\end{gathered}
$$

where $i$ - the network node number; $U_{i}$ - the voltage of the fundamental frequency; $U_{\min }, U_{\max }$ - the normative minimum and maximum voltages of the fundamental frequency; $\cos \varphi-$ the power factor at the connection 
node of the plant to the supply network; $K_{U(n) f}$ - the $n$ th harmonic factor of voltage after installation of the active filter; $K_{U(n) \min }, K_{U(n) \max }$ - the normative maximum and minimum of the $n$-th harmonic factor of voltages; $K_{U f}-$ the total harmonic distortion after installation of the active filter; $K_{U \text { min }}, K_{U \max }-$ the normative maximum and minimum of the total harmonic distortion; $K_{I(n) f}-$ the $n$-th harmonic factor of current after installation of the active filter; $K_{I(n) \min }$, $K_{I(n) \max }$ - the normative maximum and minimum of the $n$-th harmonic factor of current. Constraint (2) was established by the company "Kua Ong-Vinakomin".

The optimization problem consists of three subproblems:

1) calculation of the apparent power of the active filter to provide the normative $\cos \varphi$;

2) calculation of the apparent power of the active filter to eliminate current harmonics;

3) calculation of the apparent power of the active filter to eliminate current interharmonics.

The first subproblem is formulated in such a way: the total active power losses in the network of the fundamental frequency $\left(\Delta P_{(1)}\right)$ should be minimal, i.e.

$$
\Delta P_{(1)}=\min
$$

Constraints (2) and (3) in this case should be fulfilled. If the node for active filter installation is not assigned, all nodes of the network must be considered as candidates for the active filter installation. The algorithm must consider transformer capabilities of voltage control on the lower side with the connected load. The suggested algorithm was developed based on the software "SDO" to calculate electric network modes of the fundamental frequency $[9,10]$. The block-diagram of the algorithm is presented in Fig. 2.

Block 1. Input of initial information on the electric network scheme.

Block 2. Assignment of the number of regulating transformer tap $k, k=\overline{1, K}, \quad K-$ the quantity of regulating taps.

Block 3. Assignment of the reactive power value of the active filter, at the first step $Q_{A F}=0$.

Block 4. Calculation of the network mode using the software "SDO".

Block 5. Calculation of $\cos \varphi$ at the connection node of the power supply system of the plant to the supply network based on the results of calculation by the software "SDO" as $\cos \varphi_{c}=P_{i j} / \sqrt{P_{i j}^{2}+Q_{i j}^{2}}$, where "c" abbreviated from "calculated", $P i j$ and $Q_{i j}-$ the active and reactive powers.

Block 6. Test on fulfillment of constraint (2). If it is fulfilled, go to Block 7, otherwise go to Block 8 .

Block 7. Test on fulfillment of constraint (3) at all network nodes. If it is fulfilled, then go Block 9, otherwise - to Block 8 .

Block 8. Calculation of the reactive power of the active filter. The reactive power is calculated as

$$
Q_{A F}=P_{i j}\left(\operatorname{tg} \varphi_{c}-\operatorname{tg} \varphi_{d}\right),
$$

where "d" abbreviated from "desired". The value of $\operatorname{tg} \varphi_{c}$ is determined based on $\cos \varphi_{c}$. The value of $\operatorname{tg} \varphi_{d}$ is calculated using constraint (2). As far as the admissible value of $\cos \varphi$ is within the interval

$$
\cos \varphi_{\min } \leq \cos \varphi \leq \cos \varphi_{\max } \text {. }
$$

The value of the reactive power of the active filter is also within the interval

$$
Q_{\text {min }} \leq Q_{A F} \leq Q_{\text {max }} .
$$

The required phase angle $\varphi_{d}$ should be calculated using $\cos \varphi_{\min }$ and $\cos \varphi_{\max }$. The highest and lowest values of $Q_{A F}$ are calculated by the expressions

$$
Q_{\text {min }}=P_{i j}\left(\operatorname{tg} \varphi_{c}-\operatorname{tg} \varphi_{\min }\right), Q_{\max }=P_{i j}\left(\operatorname{tg} \varphi_{c}-\operatorname{tg} \varphi_{\max }\right) .
$$

Block 9. Calculation of the total active power losses in the network on the basis of results obtained by the software "SDO".

Block 10. Comparison of the active power losses of the preceding calculation step with the losses of the current step to determine minimum losses, namely, if

$$
\Delta P_{(1)}<\Delta P_{\text {min }} \text {, then } \Delta P_{\text {min }}=\Delta P_{(1)} \text {. }
$$

Block 11. Change of the number of the regulating transformer tap $k=k+1$. If $k>K$, then go to Block 12 , if the condition is not fulfilled, then go to Block 2.

Block 12. Active power losses caused by harmonics in the network should be minimal, i.e.

$$
\sum_{n=2}^{N} \Delta P_{(n)}=\min
$$

Constraints (4) - (6) should be met in this case by elimination of the harmonics of current with the help of the active filter at the node of filter connection. The apparent harmonic power is calculated in accordance with [13] as $S_{n \Sigma}=\sqrt{P_{n}^{2}+Q_{n}^{2}}$, where

$$
P_{n}=\sum_{n=2}^{N} U_{n} I_{n} \cos \varphi_{n}, Q_{n}=\sum_{n=2}^{N} U_{n} I_{n} \sin \varphi_{n}
$$

were calculated by the measured voltages $U_{n}$, currents $I_{n}$ and phase angle $\varphi_{n}$.

Block 13. The active power losses caused by the interharmonics in the network should be minimal, i.e.

$$
\sum_{m=1.5}^{M} \Delta P_{(m)}=\min
$$

For this purpose the interharmonics of current should be eliminated by the active filter at the node of filter connection. The apparent power of interharmonics is


$U_{m}$ and currents $I_{m}$.

Block 14. Calculation of the apparent power of the active filter as a sum of three powers:

$$
S_{A F}=S_{Q_{A F}}+S_{n \Sigma}+S_{m \Sigma} \text {. }
$$

Block 15. Output of calculation results. 


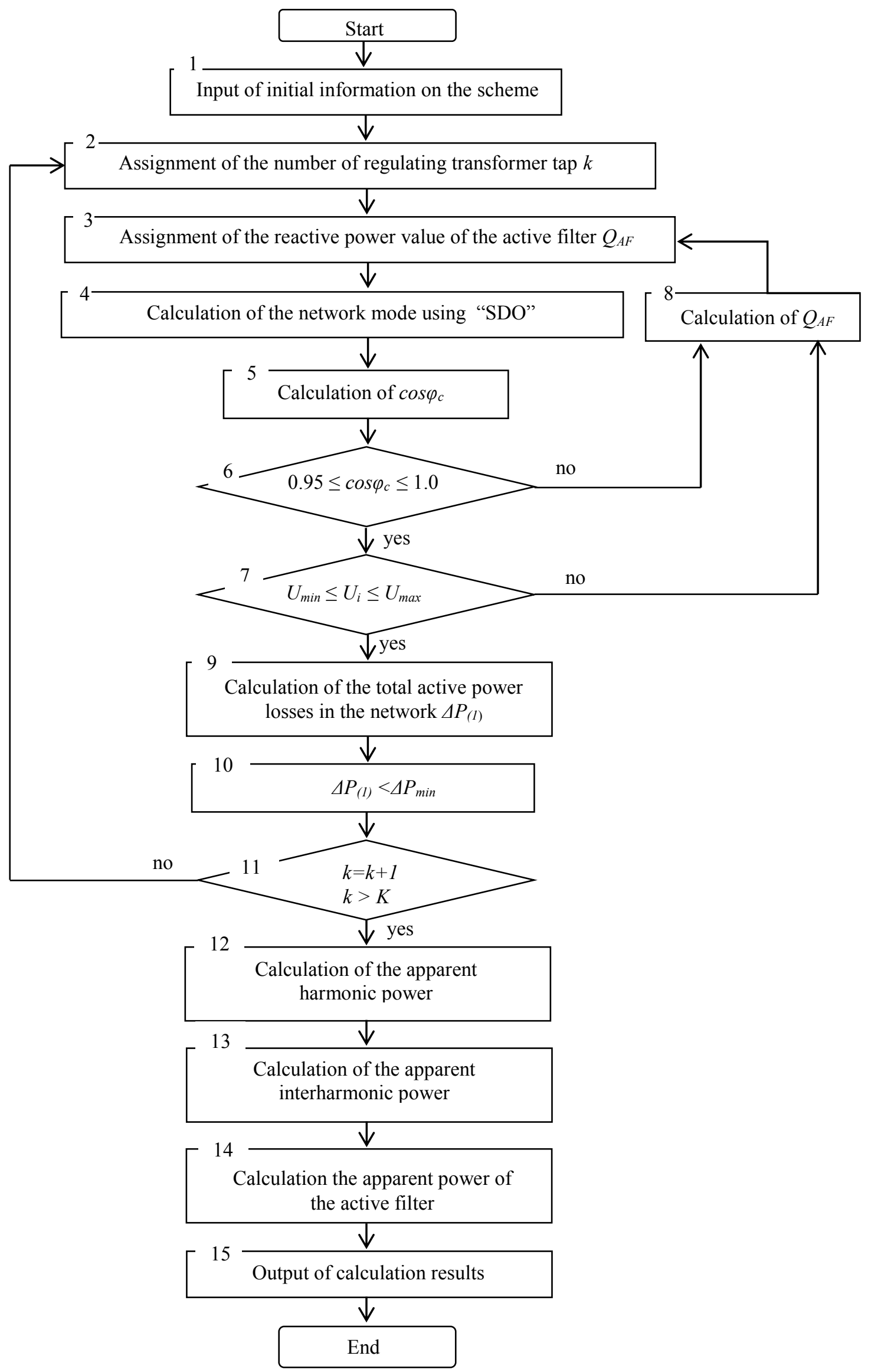

Fig. 2. Block-diagram of the algorithm to determine the power of the active filter. 


\section{Determination of the apparent power of the active filter for the coal grading plant of the company "Kua Ong- Vinakomin"}

The management company of the coal grading plant has chosen node 45038 for installation of an active filter in power supply system (Fig. 1). The transformer supplying electric energy to the power supply system of the plant has 5 regulating taps. They make it possible to have at node 4143 the following voltages: $0.38 \mathrm{kV}, 0.39 \mathrm{kV}, 0.4$ $\mathrm{kV}, 0.41 \mathrm{kV}$, and $0.42 \mathrm{kV}$. The calculation results of the software show that if the voltages at node 4143 change from $0.38 \mathrm{kV}$ to $0.42 \mathrm{kV}$, at 57 network nodes of $0.4 \mathrm{kV}$ the voltages range from $0.36 \mathrm{kV}$ to $0.39 \mathrm{kV}$. Hence, the requirements of [2] are not fulfilled. The load power factor at node 4143 in this case takes the values from $0.88 \mathrm{kV}$ to $0.99 \mathrm{kV}$, which answers incompletely to the requirements of the company. Thus, generation of reactive power can increase voltage values at the system nodes and the load power factor at node 4143.

The software "SDO" in accordance with the proposed algorithm was applied to calculate the reactive power value of the active filter. The calculation results are presented in Tables 5 and 6 . The lowest active power losses in the network equal to $110-120 \mathrm{~kW}$ are observed with the regulating tap of the $0.42 \mathrm{kV}$ transformer and the values of reactive power of the active filter of 410$580 \mathrm{kVAr}$. And all the conditions on voltage values at the network nodes and at node 4143 are met. Harmonic powers were calculated based on the measured parameters and shown in Table 7 . The active filter to eliminate harmonics of current must be no less than 17 $\mathrm{kVA}$ in each phase.

Table 5. $Q_{A F}$ and $\Delta P_{(1) \Sigma}$ calculated by the algorithm.

\begin{tabular}{|l|c|c|}
\hline$U_{4143}, k V$ & $Q_{A F}, k V A r$ & $\Delta P_{(I) \Sigma}, k W t$ \\
\hline 0.38 & $300-350$ & $297-311$ \\
\hline 0.39 & $445-480$ & $290-294$ \\
\hline 0.40 & $250-330$ & $192-297$ \\
\hline 0.41 & $245-450$ & $134-157$ \\
\hline 0.42 & $410-580$ & $110-120$ \\
\hline
\end{tabular}

Table 6. $U_{\min }, U_{\max }$, and $\cos \varphi 4143$ calculated by the algorithm.

\begin{tabular}{|l|c|c|c|}
\hline$U_{4143,}, k V$ & $\cos \varphi 4143$ & $U_{\min }, k V$ & $U_{\max }, k V$ \\
\hline 0.38 & $0.95-0.98$ & $\mathbf{0 . 3 7}$ & 0.39 \\
\hline 0.39 & $0.96-0.97$ & 0.38 & 0.39 \\
\hline 0.40 & $0.99-1.00$ & 0.38 & 0.39 \\
\hline 0.41 & $0.98-1.00$ & 0.38 & 0.41 \\
\hline 0.42 & $0.97-1.00$ & 0.38 & 0.41 \\
\hline
\end{tabular}

Table 7. Active, reactive and apparent powers of harmonics.

\begin{tabular}{|l|c|c|c|}
\hline Parameter & Phase A & Phase B & Phase C \\
\hline$P_{n}, \mathrm{kWt}$ & 8.9 & 9.6 & 7.2 \\
\hline$Q_{n}, \mathrm{kVAr}$ & 11.0 & 10.3 & 14.4 \\
\hline$S_{n}, \mathrm{kVA}$ & 14.1 & 14.1 & 16.1 \\
\hline
\end{tabular}

Table 8 presents the values of phase powers of interharmonics and the total powers of three phases that were calculated by the measured parameters. The apparent power of interharmonics at three phases accounts for $313.7 \mathrm{VA}$.

Table 8. Apparent powers of interharmonics.

\begin{tabular}{|c|c|c|c|c|c|c|c|c|c|c|c|}
\hline \multirow{2}{*}{$S_{m}, V A$} & \multicolumn{11}{|c|}{ Interharmonic } \\
\hline & 1.5 & 3.5 & 5.5 & 7.5 & 9.5 & 11.5 & 13.5 & 15.5 & 17.5 & 19.5 & 21.5 \\
\hline Phase A & 16.6 & 6.0 & 5.1 & 4.3 & 3.9 & 5.1 & 5.1 & 4.5 & 7.5 & 8.5 & 9.6 \\
\hline Phase B & 17.2 & 4.8 & 5.0 & 2.7 & 2.5 & 3.7 & 2.2 & 1.7 & 1.9 & 2.7 & 3.2 \\
\hline Phase C & 18.0 & 7.3 & 6.4 & 5.3 & 5.1 & 5.0 & 5.2 & 4.8 & 9.2 & 9.7 & 7.5 \\
\hline$S_{m \Sigma A, B, C}$ & 51.8 & 18.1 & 16.5 & 12.3 & 11.5 & 13.8 & 12.5 & 11.0 & 18.6 & 20.9 & 20.3 \\
\hline \multirow{2}{*}{$S_{m}, V A$} & \multicolumn{11}{|c|}{ Interharmonic } \\
\hline & 23.5 & 25.5 & 27.5 & 29.5 & 31.5 & 33.5 & 35.5 & 37.5 & 39.5 & 41.5 & 43.5 \\
\hline Phase A & 13.1 & 12.5 & 7.0 & 7.5 & 5.4 & 4.7 & 3.3 & 2.4 & 2.8 & 1.8 & 1.3 \\
\hline Phase B & 3.0 & 2.7 & 1.9 & 1.4 & 1.1 & 0.9 & 0.9 & 0.7 & 0.6 & 0.5 & 0.5 \\
\hline Phase C & 5.7 & 6.5 & 3.8 & 3.6 & 2.0 & 1.8 & 1.5 & 2.0 & 1.6 & 1.0 & 0.9 \\
\hline$S_{m \Sigma A, B, C}$ & 21.8 & 21.7 & 12.7 & 12.5 & 8.5 & 7.4 & 5.7 & 5.1 & 5.0 & 3.3 & 2.7 \\
\hline
\end{tabular}

\section{Conclusions}

The measurements have shown that the load current contains harmonics and interharmonics, the indices $K_{U(n)}$ and $K_{U}$ exceed the normative values, and $\cos \varphi$ is lower than the norm.

The total harmonic distortion reduction and the load power factor increase can be achieved by installation of the active filter. The power of the active filter was determined by the developed optimization algorithm and using the results of measurements of mode parameters of network.
The power of the active filter was determined for the coal grading plant of the company "Kua OngVinakomin".

The research is conducted in the framework of the research projects №AAAA-A17-117030310432-9 and №AAAA-A17$117030310438-1$ of the program of fundamental research of Siberia Branch of the Russian Academy of Sciences III.17.4.

\section{References}


1. Circular No. 39/2015/TT-BCT of $11 / 18 / 2015$ of the Ministry of Industry and Trade of Vietnam for the distribution of electrical energy

2. National Technical Regulation on Electric Power. Vietnam, 2015

3. Shekh Saddam Husen, Pinkal J. Patel, A literature review and industrial survey on active power filter, International journal of engineering development and research, Vol. 2, No 1, 118-125 (2014)

4. M.El. Habrouk, M.K. Darwish, P. Mehta, Active power filter: A review, IEEE Proceedings in Electric Power Applications, Vol. 147, No. 5, 403-413 (2000)

5. F.J. Gimeno-Sales, Abellan Antonio, Achieving maximum efficiency in three-phase systems with a shunt active power compensator based on IEEE Std. 1459, IEEE Transactions on Industrial Electronics, Vol. 23, No. 2, 812-822 (2008)

6. Vahid Chakeri, Mehrdad Tarafdar Hagh, Optimal allocation of the distributed active filters based on total loss reduction, International Journal of Smart Electrical Engineering, Vol. 6, No. 4, 171-175 (2017)
7. Seyed Abbas Taher, Mohammad Hosein Alaee, Model predictive control of PV-based shunt active power filter in single phase low voltage grid using conservative power theory, Power Electronics, Drive Systems\&Technologies Conference (PEDSTC) (2017)

8. Operating Manual Network Analyzer PQ-Box 150. Power-Quality Evaluation Software. URL: http://www.a-eberle.de

9. O.N.Voitov, E.V.Popova,L.V.Semenova, Algorithms for load flow calculation in electric networks in terms of temperature of overhead line conductors and their implementation, Elektrichestvo, No. 3, 1926 (2013)

10. Conformance certificate No. ROSS RU SP20 N00008 "Software SDO-7 for analysis, optimization of steady states and evaluation of electric power losses in electric networks" - Certificate scheme GOST R Gosstandart Rossii. Expiration date: from 31.01.2009 to 31.01.2012.

11. A.E. Emanuel, Power definitions and physical mechanism of power flow (John Wiley \& Sons, 2010) 